\title{
Patient-reported outcomes in palliative gastrointestinal stenting: a Norwegian multicenter study
}

\author{
Lene Larssen - Asle W. Medhus • Marianne J. Hjermstad • Hartwig Körner • \\ Tom Glomsaker • Taran Søberg • Dagfinn Gleditsch • Øistein Hovde • \\ Arild Nesbakken · Jan K. Tholfsen · Knut Skreden · Truls Hauge
}

Received: 9 July 2010/ Accepted: 14 March 2011/Published online: 13 April 2011

(C) The Author(s) 2011. This article is published with open access at Springerlink.com

\begin{abstract}
Background The clinical effect of stent treatment has been evaluated by mainly physicians; only a limited number of prospective studies have used patient-reported outcomes for this purpose. The aim of this work was to study the clinical effect of self-expanding metal stents in treatment of malignant gastrointestinal obstructions, as evaluated by patient-reported outcomes, and compare the rating of the treatment effect by patients and physicians. Methods Between November 2006 and April 2008, 273 patients treated with SEMS for malignant GI and biliary
\end{abstract}

L. Larssen $(\bowtie)$

Department of Medical Gastroenterology, Oslo University

Hospital, Ullevål, Kirkeveien 166, N-0407 Oslo, Norway

e-mail: lene.larssen@medisin.uio.no

L. Larssen - A. Nesbakken - T. Hauge

The Faculty of Medicine, University of Oslo, Oslo, Norway

A. W. Medhus - T. Hauge

Department of Gastroenterology, Oslo University Hospital,

Ullevål, Kirkeveien 166, N-0407 Oslo, Norway

\section{J. Hjermstad}

Department of Oncology, Regional Center for Excellence in Palliative Care, Oslo University Hospital, Ullevål, Oslo, Norway

\section{J. Hjermstad}

Department of Cancer Research and Molecular Medicine, Faculty of Medicine, Pain and Palliation Research Group,

NTNU, St. Olav University Hospital, Trondheim, Norway

H. Körner · T. Glomsaker

Department of Surgical Gastroenterology, Stavanger University

Hospital, Stavanger, Norway

H. Körner

Department of Surgical Sciences, University of Bergen, Bergen, Norway obstructions were recruited from nine Norwegian hospitals. Patients and physicians assessed symptoms independently at the time of treatment and after 2 weeks using the European Organisation for Research and Treatment of Cancer (EORTC) QLQ-C30 questionnaire supplemented with specific questions related to obstruction.

Results A total of 162 patients (99 males; median age $=72$ years) completed both assessments and were included in the study. A significant improvement in the mean global health score was observed after 2 weeks (from 9 to 18 on a $0-100$ scale, $P<0.03$ ) for all stent locations.

\section{H. Körner}

Regional Centre of Excellence in Palliative Care Western Norway, Haukeland University Hospital, Bergen, Norway

\section{T. Søberg}

Department of Internal Medicine, Østfold Hospital Trust,

Fredrikstad, Norway

D. Gleditsch

Department of Surgical Gastroenterology, Vestre Viken

Hospital Trust, Drammen, Norway

$\varnothing$. Hovde

Department of Gastroenterology, Innlandet Hospital Trust, Gjøvik, Norway

A. Nesbakken

Department of Surgical Gastroenterology, Oslo University Hospital, Aker, Oslo, Norway

\author{
J. K. Tholfsen \\ Department of Gastroenterology, Innlandet Hospital Trust, \\ Lillehammer, Norway \\ K. Skreden \\ Department of Surgical Gastroenterology, Nord-Trøndelag \\ Hospital Trust, Levanger, Norway
}


Both patients and physicians reported a significant reduction in all obstruction-related symptoms $(>20$ on the $0-100$ scale, $P<0.006)$ after SEMS treatment. The physicians reported a larger mean improvement in symptoms than did the patients, mainly because they reported more severe symptoms before treatment.

Conclusion SEMS treatment is effective in relieving symptoms of malignant GI and biliary obstruction, as reported by patients and physicians. The physicians, however, reported a larger reduction in obstructive symptoms than did the patients. A prospective assessment of patientreported outcomes is important in evaluating SEMS treatment.

Keywords Stents - Palliative care - Gastrointestinal cancer - Biliary tract neoplasm - Outcome assessment . Quality of life

Palliative treatment with self-expanding metal stents (SEMS) is regarded as a safe and highly effective procedure for relief of symptoms caused by malignant obstructions of the gastrointestinal (GI) tract [1-8]. Most studies concerning treatment with SEMS, whether randomized, comparative, or merely descriptive, focus on technical success (e.g., correct deployment of the stent), clinical success (restored passage), procedure-related complications, and cost-effectiveness. Typically, the clinical outcomes of SEMS treatment have been evaluated by the physician [9]; only a few prospective studies reported repeated symptom assessments by the patient [10-16]. Since patients' and physicians' ratings of treatment effects do not always correspond well, palliative treatment efforts such as SEMS for malignant GI obstructions should be evaluated by individual outcome measures reported by the patients as well as by the physicians [17-22].

The main objective of this multicenter study was to use patient-reported outcomes to evaluate the treatment effects of SEMS on quality of life (QoL) and symptoms related to malignant GI and biliary obstruction. An additional aim of the study was to compare patient- and physician-reported evaluations of the treatment's effects.

\section{Materials and methods}

Nine Norwegian hospitals performing SEMS treatment for GI obstructions participated in the present study. The inclusion period was from November 2006 to April 2008. Patients were eligible for consecutive inclusion according to the following criteria: (1) symptoms related to malignant GI obstruction, (2) indication for treatment with all types of metal stents established, (3) fluency in oral and written Norwegian, and (4) cognitive capability to complete the questionnaires. Patients who received their colonic stent as a "bridge to surgery" (i.e., to relieve the acute obstruction prior to elective surgery) and underwent bowel resection within 2 weeks after stent placement were not asked to complete the questionnaire after 2 weeks and were thus not included in the analyses. The study was approved by the Regional Committee for Medical Research Ethics in Southern Norway and the Data Protection Supervisor at Oslo University Hospital, Ullevål. All patients received oral and written information about the study. Written informed consent was obtained from all participants.

\section{Stent procedure}

All stents were deployed endoscopically under fluoroscopic guidance. Both covered and uncovered stents were used for esophageal and biliary stent treatment, while uncovered stents were used in other locations.

\section{Assessment of patient-reported outcomes}

The European Organisation for Research and Treatment of Cancer Core Quality of Life Questionnaire, EORTC QLQC30, version 3.0 [23], was used to assess patient-reported outcomes, supplemented with selected questions from other relevant EORTC organ- and disease-specific modules (http://www.eortc.be/). The EORTC QLQ-C30 is a cancerspecific 30-item self-reporting questionnaire consisting of both multi-item scales and single-item measures. These include five functional scales (i.e., physical, role, cognitive, emotional, and social), three symptom scales (i.e., fatigue, nausea/vomiting, and pain), and six single items (i.e., dyspnea, insomnia, appetite loss, constipation, diarrhea, and financial problems), as well as two questions where the patients assessed their overall health and QoL on a scale from 1 to 7 . Combining these two scores resulted in a global health score.

EORTC recommends that organ-specific modules be used in addition to the core questionnaire to capture diagnosis- or treatment-specific problems. For the purpose of the present study, a selection of questions was made from the relevant organ-specific modules to reduce the respondent's burden and to focus on specific problems pertaining to the different diagnostic or stent groups. Questions to be answered by the patients receiving esophageal, biliary, and colonic stents were selected from the stomach module EORTC QLQ-STO22 [24], the pancreatic module EORTC QLQ-PAN26 [25], and the colorectal module EORTC QLQ-CR38 [26], respectively (Table 2). Patients who received gastroduodenal stents did not answer any 
additional questions as their main obstruction-related symptoms, nausea and vomiting, were specifically addressed by the core questionnaire.

Higher scores on the symptom scales and single items from the core questionnaires and the organ-specific modules indicated more severe symptoms, while higher scores on the functional scales indicate better functioning. All items were to be answered on an ordinal scale ranging from 1 ("Not at all") to 4 ("Very much"), except for the two modified visual analog scales assessing global health and QoL; they ranged from 1 to 7 . The time frame was the past 7 days. Scale and item scores were transformed into a continuous scale from 0 to 100 , as described in the EORTC Scoring Manual [27]. A mean score difference of 5-10 is usually regarded as a small but clinically noticeable change for the patients, a change between 10-20 as moderate, and $>20$ as a large clinical change [28, 29].

\section{Administration of questionnaires}

All assessments were performed twice, at inclusion (-2 to +1 day before/after the procedure) and 2 weeks after treatment. The questionnaire was administered to the study participants upon admission by the treating physician or a study nurse. The same questionnaire was given to the patients when leaving the hospital. The patients were instructed to complete the second questionnaire 2 weeks after stent treatment and return it by mail. The 2-week time span between assessments was chosen to reach the maximum effect of the stent treatment and reduce the impact of disease progression. To reduce the influence of recall bias, the patients had to complete the initial questionnaire no later than the day after the procedure and the second questionnaire no later than 3 weeks after treatment. The physicians assessed the same organspecific symptoms at inclusion and the second assessment at hospital discharge or 2 weeks after stent treatment if the patient was still hospitalized. The same physician was responsible for the before and after assessment of symptoms.

\section{Statistical analysis}

Power calculations were based on a mean change of 10 with a standard deviation (SD) of 15 of global health, with $90 \%$ power and a $5 \%$ level of significance, which yielded a sample size of 26 patients in each of the treatment groups for the four stent locations. Wilcoxon signed-rank test with 5\% significance level was used when evaluating changes of symptoms before and after treatment. Statistical analyses were performed using SPSS 16.0 (SPSS, Inc., Chicago, IL).

\section{Results}

\section{Patient characteristics}

A total of 273 patients were eligible for inclusion in the study, varying from 2 to 105 patients at the nine participating centers. Two hundred thirty-eight (87\%) patients completed the questionnaire prior to the stent procedure, and $162(68 \%)$ of these completed both questionnaires. Twenty-seven patients did not return the second form for unknown reasons (Fig. 1). Ninety-nine males and 63 females with a median age of 72 years were included. Clinical and demographic characteristics are given in Table 1. The most frequent diagnoses were cancer of the colon and pancreas. Of the 18 patients with gastric cancer who received stents, eight had obstructions located in the cardia ventriculi and were treated with esophageal stents. Ten patients had gastric outlet obstruction and were treated with duodenal stents.

\section{Patient-reported outcomes}

Patients reported a clinically and statistically significant reduction in all obstruction-related symptoms in all four stent locations, with a mean reduction of at least 20 $(P<0.02)$. Furthermore, a clinically and statistically significant improvement in global health function $(P<0.03)$ was observed in all treatment groups. Additionally, various other symptoms improved significantly: nausea/vomiting (colon and biliary), appetite loss (biliary and gastroduodenal), pain (gastroduodenal and colonic), and constipation (colonic) (Tables 2, 3, 4, and 5). The total numbers of patients experiencing symptomatic improvement $\geq 20$, improvement $<20$, or worsening are reported in Table 6 .

The scorings from patients who completed the pretreatment questionnaire before treatment were similar to those from patients who completed it the day after treatment. Sixty-four patients $(40 \%)$ completed the first assessment the day after stent insertion because of emergency stent treatment or pronounced symptoms before treatment. The rate of missing items was low, 0.9 and $1.0 \%$ in the two assessments, respectively. For the multi-items scales, missing values were assigned according to a standard scoring procedure (EORTCs scoring manual, [27]) by replacing missing items with the scale mean values, provided that half or more of the scale items were completed.

Comparison of symptoms evaluated by patients and physicians

When comparing the patients' and physicians' scores, a significant difference in the answers of six of seven 


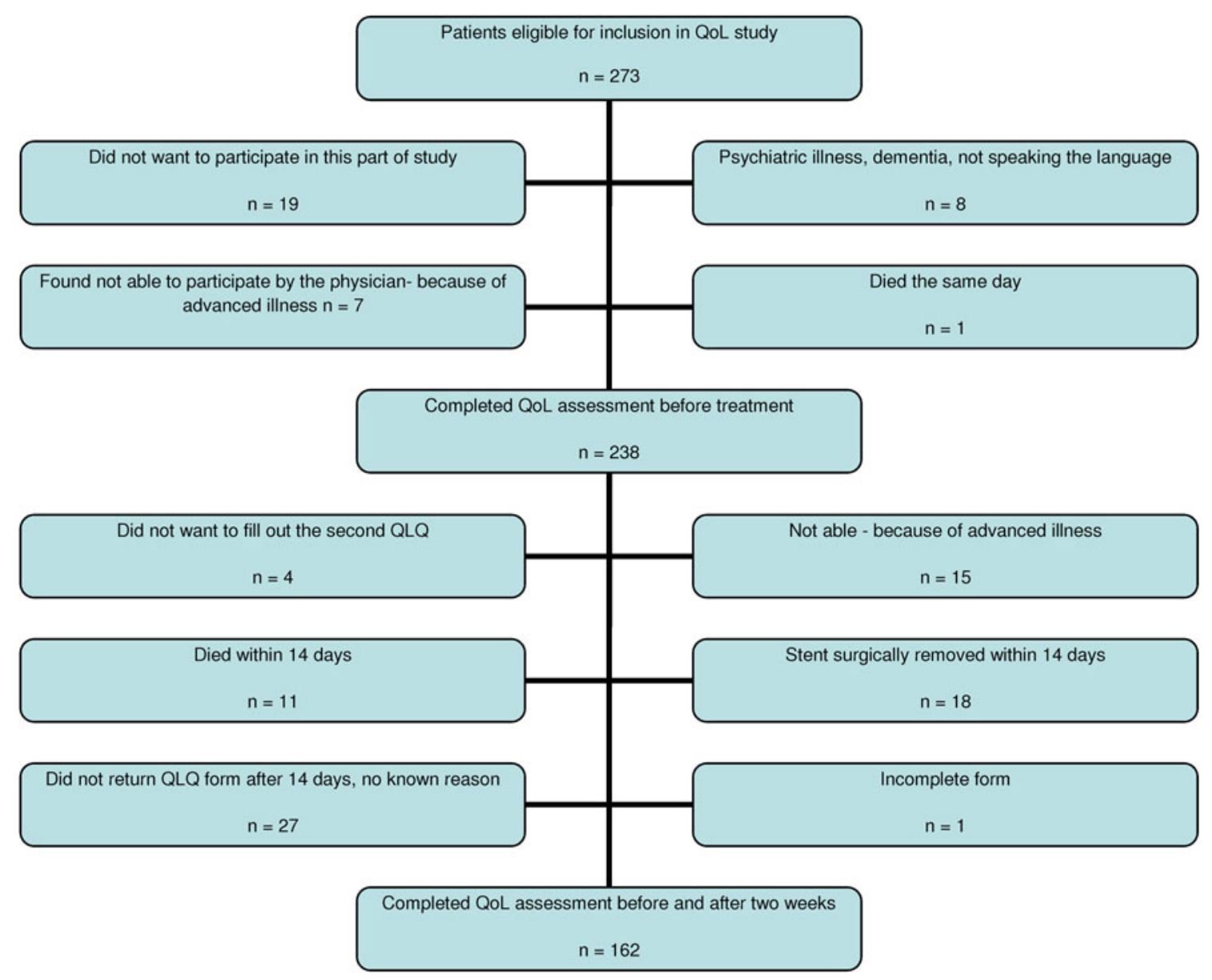

Fig. 1 Flowchart showing the selection of the 162 patients included in this study

questions before treatment was found, whereby the physicians indicated symptoms as more pronounced than the patients $(P<0.02)$. However, when comparing the posttreatment evaluation, the scores tended to be similar (a statistically significant difference was found for two questions, see Table 7). When evaluating the clinical effect as an improvement in obstructive symptoms, the physicians reported a larger mean reduction in obstructive symptoms and, thus, a better treatment effect as compared to the patients.

The median hospital stay was 4 days (range $=0-64$ ). Therefore, physicians completed their second symptom assessment $<7$ days after the first registration in (131/162) $81 \%$ of the cases. The patients completed their second assessment of symptoms after 2 weeks (assessing symptoms between days 7 and 14).

\section{Short-term outcome/complications}

During the first week, 12 of 162 patients (7\%) experienced complications: three nonfunctional stents, two stent migrations, two bleeding episodes, two episodes of cholangitis, one tracheal-esophageal fistula, one stent obstruction by food impaction, and one stent obstruction by tumor overgrowth. There was no procedure-related mortality.

\section{Discussion}

This study is one of very few that evaluates the symptomatic effect of palliative GI stenting based on patientreported outcomes. Furthermore, to our knowledge it is the first to compare patients' and physicians' assessments of the symptomatic effect of SEMS treatment. The present study demonstrates that the majority of patients found treatment with SEMS effective in relieving obstructive symptoms in all GI tract locations. Additionally, patients reported a significant clinical improvement in global health after 2 weeks for all four stent locations. The physicians tended to evaluate pretreatment symptoms as more severe than did the patients. The postprocedure scorings were more similar.

This study shows that treatment with SEMS is effective in relieving symptoms related to malignant GI obstruction. 
Table 1 Clinical and demographic characteristics of 162 patients treated by self-expanding metal stents for malignant gastrointestinal obstruction

\begin{tabular}{ll}
\hline Age [median (range)] & $72(33-93)$ \\
Gender M/F & $99 / 63$ \\
Survival [median (range)] (days) & $111(15-535)$ \\
Diagnoses & \\
Colon cancer & $49(30 \%)$ \\
Pancreatic cancer & $41(25 \%)$ \\
Gastric cancer & $18(11 \%)$ \\
Esophageal cancer & $28(17 \%)$ \\
Bile duct cancer & $9(6 \%)$ \\
Other malignancies ${ }^{\mathrm{a}}$ & $17(11 \%)$ \\
& \\
Other palliative treatment & $18(11 \%)$ \\
Chemotherapy (during day 0-14) & $7(4 \%)$ \\
Radiotherapy (during day 0-14) & \\
Stent locations & $41(25 \%)$ \\
Esophageal & $33(20 \%)$ \\
Gastroduodenal & $40(25 \%)$ \\
Biliary & $48(30 \%)$ \\
Colon
\end{tabular}

a Breast cancer, $n=1$, lymphoma, $n=1$; lung cancer, $n=3$; prostate cancer, $n=2$; hepatocellular carcinoma, $n=1$; gallbladder cancer, $n=1$; thyroid cancer, $n=1$; papillary cancer, $n=1$; ovarian cancer, $n=3$; duodenal cancer, $n=1$; malignant melanoma, $n=2$

Our conclusion is strengthened by the fact that patients in this study were treated at small local centers, not large expert centers. SEMS as palliative principle seems to be effective independent of location. With regard to the symptomatic effect on esophageal and gastric outlet obstructions, our findings are in accordance with previous studies.
Table 3 EORTC C $30^{a}$ results from 33 patients treated with gastroduodenal stents

\begin{tabular}{|c|c|c|c|c|}
\hline & Before & After & Difference & $P$ value \\
\hline $\begin{array}{l}\text { Global health } \\
\text { function }^{\mathrm{b}}\end{array}$ & $22.0(19.3)$ & $38.4(26.4)$ & $16.4(24.8)$ & $<0.001$ \\
\hline \multicolumn{5}{|l|}{ Symptom scales } \\
\hline Pain & $57.6(28.6)$ & $39.9(36.3)$ & $17.7(36.3)$ & 0.014 \\
\hline Nausea/vomiting & $63.1(31.1)$ & $30.3(27.5)$ & $32.8(38.7)$ & $<0.001$ \\
\hline \multicolumn{5}{|l|}{ Single items ${ }^{\mathrm{b}}$} \\
\hline Appetite loss ${ }^{\mathrm{c}}$ & $81.8(25.1)$ & $65.7(37.7)$ & $16.2(34.5)$ & 0.013 \\
\hline
\end{tabular}

All values are mean $(\mathrm{SD})$

a A selection of the EORTC QLQ-C30 most relevant scorings was made; no significant change was found in the excluded scores

b Scale from 0 to 100; high scores represent more severe symptoms

c Scale from 0 to 100; high scores represent higher level of overall functioning

Additionally, were we able to find significantly improved general well-being and better QoL, which most previous studies had not been able to document [10, 12]. A study of colon obstruction using patient-reported outcomes ended early and was therefore not able to make a conclusion [30].

That physicians' and patients' perceptions of symptoms differ is in line with previous studies in palliative medicine that compared physicians and patients, although underestimation of patients' symptoms by physicians is more common [17-21]. We do not know the reasons for the discrepancies in scoring found in our study; but one plausible explanation may reflect the enthusiasm of the physicians performing these procedures and their needs to justify the indication. The study was not designed to clarify this question.

Table 2 Scores from EORTC C30 ${ }^{\mathrm{a}}$ and selected obstruction-related questions from EORTC OES 18 given by 41 patients treated with esophageal stents

\begin{tabular}{|c|c|c|c|c|}
\hline & Before & After & Difference & $P$ value \\
\hline Global health function ${ }^{\mathrm{b}}$ & $30.0(18.0)$ & $39.1(26.1)$ & $9.2(26.4)$ & 0.03 \\
\hline \multicolumn{5}{|l|}{ Symptom scales ${ }^{\mathrm{a}, \mathrm{c}}$} \\
\hline Nausea/vomiting & $37.8(31.0)$ & $33.7(31.7)$ & $4.1(39.6)$ & 0.49 \\
\hline Pain & $43.5(29.6)$ & $51.2(31.5)$ & $-7.7(34.6)$ & 0.20 \\
\hline \multicolumn{5}{|l|}{ Single items ${ }^{\mathrm{c}}$} \\
\hline Appetite loss & $69.1(38.3)$ & $61.8(39.1)$ & $7.3(41.8)$ & 0.31 \\
\hline \multicolumn{5}{|l|}{ Organ-specific questions from EORTC OES $18^{c}$} \\
\hline Have you had problems eating solid food? & $86.8(26.3)$ & $51.0(40.1)$ & $36.0(51.6)$ & $<0.001$ \\
\hline Have you had problems eating liquidized or soft food? & $63.1(35.3)$ & $30.0(37.3)$ & $32.4(52.3)$ & 0.001 \\
\hline Have you had problems drinking liquids? & $38.6(36.8)$ & $16.7(26.5)$ & $22.0(41.2)$ & 0.002 \\
\hline
\end{tabular}

All values are mean $(\mathrm{SD})$

a A selection of the EORTC QLQ-C30 most relevant scorings was made; no significant change was found in the excluded scores

b Scale from 0 to 100; high scores represent higher level of functioning

c Scale from 0 to 100; high scores represent more severe symptoms 
Table 4 Scores from EORTC C30 and selected obstruction-related questions from EORTC PAN26 from 40 patients treated with biliary stents

\begin{tabular}{lllll}
\hline & Before & After & Difference & $P$ value \\
\hline $\begin{array}{l}\text { Global health } \\
\text { function }\end{array}$ & $30.4(25.9)$ & $48.3(28.0)$ & $17.9(34.3)$ & 0.003 \\
Symptom scales $^{\mathrm{c}}$ & & & & \\
$\quad$ Pain & $48.3(36.2)$ & $28.8(25.0)$ & $19.6(31.8)$ & 0.001 \\
Nausea/vomiting & $35.0(30.8)$ & $21.3(23.3)$ & $13.8(28.7)$ & 0.005 \\
Single items & & & & \\
$\quad$ Appetite loss & $61.7(41.0)$ & $45.8(41.8)$ & $15.8(32.0)$ & 0.007 \\
$\begin{array}{l}\text { Organ-specific questions from EORTC PAN 26 } \\
\text { Have you been } \\
\text { itching? }\end{array}$ & $46.6(39.1)$ & $23.3(32.2)$ & $23.3(51.3)$ & 0.01 \\
\end{tabular}

All values are mean $(\mathrm{SD})$

${ }^{a}$ A selection of the EORTC QLQ-C30 most relevant scorings was made; no significant change was found in the excluded scores

b Scale from 0 to 100; high scores represent higher level of overall functioning

c Scale from 0 to 100; high scores represent more severe

The physicians completed the second questionnaire earlier than the patients (earlier than day 7 for $81 \%$ of the patients). The study protocol did not include a scheduled follow-up after stent treatment. The patients were often severely ill, with long travelling distance to hospital, and an extra hospital visit to allow the physician to perform a symptom assessment was hence not included in the followup. As the hospital stay related to the stent procedure usually was of short duration, the physicians' scoring often had to be performed at discharge from hospital. However, it is likely that the questionnaire's 1-week time format reduced the influence of the discrepancy of when the physicians and patients did the second assessment.

Although there were significant improvements for the group in total, there was interindividual variation and some patients did not experience improvement in their obstructive symptoms. A review of the medical charts revealed that absence of symptomatic improvement often could be explained by dysfunctional stents, migrations, infections, pain, or intercurrent diseases during the first 2 weeks. This represented a limited number of patients and separate subanalyses were not performed. Furthermore, ongoing treatment with other modalities (e.g., chemotherapy) can potentially influence symptom scoring negatively. We found no significant difference in the scorings of the 25 patients who received chemo- and/or radiation therapy during the assessment period.

Table 5 Scores from EORTC C30 a and selected questions from EORTC CR38 from 46 patients treated with colon stents

\begin{tabular}{|c|c|c|c|c|}
\hline & Before & After & Difference & $P$ value \\
\hline Global health function ${ }^{\mathrm{b}}$ & $38.0(24.8)$ & $48.7(23.7)$ & $10.7(24.5)$ & 0.009 \\
\hline \multicolumn{5}{|l|}{ Symptom scales ${ }^{\mathrm{a}, \mathrm{c}}$} \\
\hline Pain & $49.3(33.9)$ & $28.4(30.0)$ & $20.9(39.0)$ & 0.001 \\
\hline Nausea /vomiting & $29.4(34.1)$ & $13.8(21.5)$ & $15.6(33.6)$ & 0.003 \\
\hline \multicolumn{5}{|l|}{ Single items ${ }^{c}$} \\
\hline Appetite loss & $45.4(40.8)$ & $31.9(35.4)$ & $13.5(45.4)$ & 0.04 \\
\hline Constipation & $53.9(43.7)$ & $24.8(32.2)$ & $29.1(46.0)$ & $<0.001$ \\
\hline Diarrhea & $37.6(37.2)$ & $45.4(33.6)$ & $-7.8(45.7)$ & 0.26 \\
\hline \multicolumn{5}{|c|}{ Organ-specific questions from EORTC CR $38^{c}$} \\
\hline Have you had abdominal pain? & $53.6(38.2)$ & $32.6(28.5)$ & $21.0(37.4)$ & $<0.001$ \\
\hline Have you felt bloated? & $67.4(36.2)$ & $27.5(30.0)$ & $40.0(44.8)$ & $<0.001$ \\
\hline
\end{tabular}

All values are mean $(\mathrm{SD})$

a A selection of the EORTC QLQ-C30 most relevant scorings was made; no significant change was found in the excluded scores

b Scale from 0 to 100; high scores represent higher level of overall functioning

c Scale from 0 to 100; high scores represent more severe symptoms

Table 6 Patient-reported symptomatic effect of stent treatment

\begin{tabular}{llr}
\hline & $\begin{array}{l}\text { Number of patients with clinical } \\
\text { effect on } \geq 1 \text { symptoms }\end{array}$ & $\begin{array}{l}\text { Number of patients with no } \\
\text { effect or worsening of symptoms }\end{array}$ \\
\hline Esophageal stent & $34(81 \%)$ & $8(19 \%)$ \\
Gastroduodenal stent & $16(48 \%)$ & $17(52 \%)$ \\
Biliary stent & $20(50 \%)$ & $20(50 \%)$ \\
Colonic stent & $33(69 \%)$ & $15(31 \%)$ \\
\hline
\end{tabular}


Table 7 Comparison of scoring by patients and physicians before and after stent treatment

\begin{tabular}{|c|c|c|c|c|c|c|c|c|c|}
\hline \multirow[b]{2}{*}{ Stent location } & \multicolumn{3}{|c|}{$\begin{array}{l}\text { Symptom score before stent } \\
\text { treatment }\end{array}$} & \multicolumn{3}{|c|}{$\begin{array}{l}\text { Symptom score after stent } \\
\text { treatment }\end{array}$} & \multicolumn{3}{|c|}{ Change in symptom score } \\
\hline & Patient & Physician & $\begin{array}{l}P \text { value } \\
\text { diff. }\end{array}$ & Patient & Physician & $\begin{array}{l}P \text { value } \\
\text { diff. }\end{array}$ & $\begin{array}{l}\text { Patient diff. } \\
\text { before/after }\end{array}$ & $\begin{array}{l}\text { Physician diff. } \\
\text { before/after }\end{array}$ & $\begin{array}{l}P \text { value } \\
\text { diff. }\end{array}$ \\
\hline \multicolumn{10}{|l|}{ Esophagus } \\
\hline $\begin{array}{l}\text { Have you had problems eating } \\
\text { solid food? }\end{array}$ & 87 & 93 & 0.13 & 51 & 58 & 0.44 & 37 & 34 & 0.78 \\
\hline $\begin{array}{l}\text { Have you had problems eating } \\
\text { liquidized or soft food? }\end{array}$ & 63 & 82 & 0.002 & 30 & 33 & 0.49 & 33 & 49 & 0.22 \\
\hline $\begin{array}{l}\text { Have you had problems drinking } \\
\text { liquids? }\end{array}$ & 39 & 64 & 0.001 & 17 & 14 & 0.63 & 25 & 50 & 0.001 \\
\hline \multicolumn{10}{|l|}{ Stomach/duodenum } \\
\hline Have you vomited? & 63 & 83 & 0.002 & 30 & 19 & 0.24 & 32 & 65 & 0.007 \\
\hline \multicolumn{10}{|l|}{ Biliary tree } \\
\hline Have you been itching? & 47 & 60 & 0.015 & 23 & 26 & 0.38 & 24 & 34 & 0.24 \\
\hline \multicolumn{10}{|l|}{ Colon } \\
\hline Have you had abdominal pain? & 54 & 70 & $<0.001$ & 33 & 12 & $<0.001$ & 21 & 58 & $<0.001$ \\
\hline Have you felt bloated? & 67 & 78 & 0.002 & 28 & 15 & 0.03 & 40 & 64 & 0.007 \\
\hline
\end{tabular}

All values are mean. Scale from 0 to 100 ; high scores represent more severe symptoms

Our study did not identify subgroups of patients that regularly did not benefit from SEMS treatment and, therefore, should have received alternative palliative treatment. This might be due to the relatively low number of patients included.

Seventy-six patients completed only the first questionnaire. However, as shown in Fig. 1, only 27 patients failed to complete the second questionnaire for unknown reasons. It is possible that these patients did not experience the expected effect of the stent treatment and that this lack of data could represent a selection bias. However, we know that these 27 patients did not differ in age, pretreatment global health, or survival from the 162 repliers. Three of these 27 patients experienced dysfunctional stents and needed reinterventions during the first 2 weeks, which might have influenced their opinion of stent function. Three patients experienced cholangitis and/or pancreatitis immediately after biliary stenting but had functional stents. For the remaining 21 of the 27 patients, there was not sufficient information in their medical records to explain why they did not return their second questionnaire.

\section{Conclusion}

SEMS treatment is effective in relieving symptoms of malignant GI and biliary obstruction, according to assessment by both patients and physicians. This study demonstrates a significant difference in how the physicians and patients evaluate treatment effects and thereby the importance of taking patient-reported outcomes into account when evaluating clinical palliative interventions. Future studies evaluating SEMS treatment should include prospective assessment of patient-reported outcomes to increase our knowledge about the efficacy of this treatment.

Acknowledgments The following hospitals participated in the study: Oslo University Hospital, Ullevål, Department of Gastroenterology, Oslo, Norway; Stavanger University Hospital, Department of Surgery, Stavanger, Norway; Østfold Hospital Trust Fredrikstad, Department of Internal Medicine, Fredrikstad, Norway; Vestre Viken Hospital Trust Drammen, Department of Surgery, Drammen, Norway; Innlandet Hospital Trust Gjøvik, Department of Internal Medicine, Gjøvik, Norway; Oslo University Hospital, Aker, Department of Surgery, Oslo, Norway; Innlandet Hospital Trust Lillehammer, Department of Internal Medicine, Lillehammer, Norway; Nord- Trøndelag Hospital Trust Levanger, Department of Surgery, Levanger, Norway; Oslo University Hospital, AHUS, Department of Surgery, Oslo, Norway.

Disclosures Lene Larssen, Asle W. Medhus, Marianne J. Hjermstad, Hartwig Körner, Tom Glomsaker, Taran Søberg, Dagfinn Gleditsch, Øistein Hovde, Arild Nesbakken, Jan K. Tholfsen, Knut Skreden, and Truls Hauge have no conflicts of interest and no financial ties to disclose.

Open Access This article is distributed under the terms of the Creative Commons Attribution Noncommercial License which permits any noncommercial use, distribution, and reproduction in any medium, provided the original author(s) and source are credited.

\section{References}

1. Dormann A, Meisner S, Verin N, Wenk LA (2004) Selfexpanding metal stents for gastroduodenal malignancies: 
systematic review of their clinical effectiveness. Endoscopy 36:543-550

2. Sebastian S, Johnston S, Geoghegan T, Torreggiani W, Buckley M (2004) Pooled analysis of the efficacy and safety of selfexpanding metal stenting in malignant colorectal obstruction. Am J Gastroenterol 99:2051-2057

3. Moss A, Morris E, Mac MP (2006) Palliative biliary stents for obstructing pancreatic carcinoma. Cochrane Database Syst Rev Cochrane Database Syst Rev 2:CD004200

4. Breitenstein S, Rickenbacher A, Berdajs D, Puhan M, Clavien PA, Demartines N (2007) Systematic evaluation of surgical strategies for acute malignant left-sided colonic obstruction. $\mathrm{Br}$ J Surg 94:1451-1460

5. Watt AM, Faragher IG, Griffin TT, Rieger NA, Maddern GJ (2007) Self-expanding metallic stents for relieving malignant colorectal obstruction: a systematic review. Ann Surg 246:24-30

6. Jeurnink SM, Steyerberg EW, Hof G, van Eijck CH, Kuipers EJ, Siersema PD (2007) Gastrojejunostomy versus stent placement in patients with malignant gastric outlet obstruction: a comparison in 95 patients. J Surg Oncol 96(5):389-396

7. Homs MY, Siersema PD (2007) Stents in the GI tract. Expert Rev Med Devices 4:741-752

8. Sreedharan A, Harris K, Crellin A, Forman D, Everett SM (2009) Interventions for dysphagia in oesophageal cancer. Cochrane Database Syst Rev 4:CD005048

9. Larssen L, Medhus AW, Hauge T (2009) Treatment of malignant gastric outlet obstruction with stents: an evaluation of the reported variables for clinical outcome. BMC Gastroenterol 9:45

10. Homs MY, Essink-Bot ML, Borsboom GJ, Steyerberg EW, Siersema PD (2004) Quality of life after palliative treatment for oesophageal carcinoma- a prospective comparison between stent placement and single dose brachytherapy. Eur J Cancer 40:18621871

11. Bergquist H, Wenger U, Johnsson E, Nyman J, Ejnell H, Hammerlid E, Lundell L, Ruth M (2005) Stent insertion or endoluminal brachytherapy as palliation of patients with advanced cancer of the esophagus and gastroesophageal junction. Results of a randomized, controlled clinical trial. Dis Esophagus 18:131139

12. van Hooft J, Mutignani M, Repici A, Messmann H, Neuhaus H, Fockens P (2007) First data on the palliative treatment of patients with malignant gastric outlet obstruction using the WallFlex enteral stent: a retrospective multicenter study. Endoscopy 39: 434-439

13. Madhusudhan C, Saluja SS, Pal S, Ahuja V, Saran P, Dash NR, Sahni P, Chattopadhyay TK (2009) Palliative stenting for relief of dysphagia in patients with inoperable esophageal cancer: impact on quality of life. Dis Esophagus 22:331-336

14. Saluja SS, Gulati M, Garg PK, Pal H, Pal S, Sahni P, Chattopadhyay TK (2008) Endoscopic or percutaneous biliary drainage for gallbladder cancer: a randomized trial and quality of life assessment. Clin Gastroenterol Hepatol 6:944-950

15. Schmidt C, Gerdes H, Hawkins W, Zucker E, Zhou Q, Riedel E, Jaques D, Markowitz A, Coit D, Schattner M (2009) A prospective observational study examining quality of life in patients with malignant gastric outlet obstruction. Am J Surg 198:92-99

16. Nagula S, Ishill N, Nash C, Markowitz AJ, Schattner MA, Temple L, Weiser MR, Thaler HT, Zauber A, Gerdes H (2010) Quality of life and symptom control after stent placement or surgical palliation of malignant colorectal obstruction. J Am Coll Surg 210:45-53

17. Wilson KA, Dowling AJ, Abdolell M, Tannock IF (2000) Perception of quality of life by patients, partners and treating physicians. Qual Life Res 9:1041-1052
18. Fromme EK, Eilers KM, Mori M, Hsieh YC, Beer TM (2004) How accurate is clinician reporting of chemotherapy adverse effects? A comparison with patient-reported symptoms from the Quality-of-Life Questionnaire C30. J Clin Oncol 22:3485-3490

19. Sonn GA, Sadetsky N, Presti JC, Litwin MS (2009) Differing perceptions of quality of life in patients with prostate cancer and their doctors. J Urol 182:2296-2302

20. Pearcy R, Waldron D, O’Boyle C, MacDonagh R (2008) Proxy assessment of quality of life in patients with prostate cancer: how accurate are partners and urologists? J R Soc Med 101:133-138

21. Petersen MA, Larsen H, Pedersen L, Sonne N, Groenvold M (2006) Assessing health-related quality of life in palliative care: comparing patient and physician assessments. Eur $\mathrm{J}$ Cancer 42:1159-1166

22. Easson AM, Lee KF, Brasel K, Krouse RS (2003) Clinical research for surgeons in palliative care: challenges and opportunities. J Am Coll Surg 196:141-151

23. Aaronson NK, Ahmedzai S, Bergman B, Bullinger M, Cull A, Duez NJ, Filiberti A, Flechtner H, Fleishman SB, de Haes JC et al (1993) The European Organization for Research and Treatment of Cancer QLQ-C30: a quality-of-life instrument for use in international clinical trials in oncology. $\mathrm{J}$ Natl Cancer Inst $85: 365-376$

24. Blazeby JM, Conroy T, Bottomley A, Vickery C, Arraras J, Sezer O, Moore J, Koller M, Turhal NS, Stuart R, Van Cutsem E, D'haese S, Coens C, European Organisation for Research, Treatment of Cancer Gastrointestinal, Quality of Life Groups (2004) Clinical and psychometric validation of a questionnaire module, the EORTC QLQ-STO 22, to assess quality of life in patients with gastric cancer. Eur J Cancer 40:2260-2268

25. Fitzsimmons D, Johnson CD, George S, Payne S, Sandberg AA, Bassi C, Beger HG, Birk D, Buchler MW, Dervenis C, Fernandez CL, Friess H, Grahm AL, Jeekel J, Laugier R, Meyer D, Singer MW, Tihanyi T (1999) Development of a disease specific quality of life (QoL) questionnaire module to supplement the EORTC Core Cancer QoL Questionnaire, the QLQ-C30 in patients with pancreatic cancer. EORTC Study Group on Quality of Life. Eur J Cancer 35:939-941

26. Sprangers MA, te Velde A, Aaronson NK (1999) The construction and testing of the EORTC colorectal cancer-specific quality of life questionnaire module (QLQ-CR38). European Organization for Research and Treatment of Cancer Study Group on Quality of Life. Eur J Cancer 35:238-247

27. Fayers PM, Aaronson NK, Bjordal K, Groenvold M, Curran D, Bottomley A, on behalf of the EORTC Quality of Life Group (2001) The EORTC QLQ-C30 Scoring Manual, 3rd edn. European Organisation for Research and Treatment of Cancer, Brussels

28. Osoba D, Rodrigues G, Myles J, Zee B, Pater J (1998) Interpreting the significance of changes in health-related quality-oflife scores. J Clin Oncol 16:139-144

29. Cocks K, King MT, Velikova G, Fayers PM, Brown JM (2008) Quality, interpretation and presentation of European Organisation for Research and Treatment of Cancer quality of life questionnaire core 30 data in randomised controlled trials. Eur J Cancer 44:1793-1798

30. van Hooft JE, Bemelman WA, Breumelhof R, Siersema PD, Kruyt PM, van der Linde K, Veenendaal RA, Verhulst ML, Marinelli AW, Gerritsen JJ, van Berkel AM, Timmer R, Grubben MJ, Scholten P, Geraedts AA, Oldenburg B, Sprangers MA, Bossuyt PM, Fockens P (2007) Colonic stenting as bridge to surgery versus emergency surgery for management of acute leftsided malignant colonic obstruction: a multicenter randomized trial (Stent-in 2 Study). BMC Surg 7:12 